\title{
Dietary calcium intake and mortality risk from cardiovascular disease and all causes: a meta-analysis of prospective cohort studies
}

\author{
Xia Wang ${ }^{1,2}$, Hongxia Chen ${ }^{3}$, Yingying Ouyang ${ }^{2}$, Jun Liü ${ }^{2}$ Gang Zhao ${ }^{4}$, Wei Bao ${ }^{2^{*}}$ and Maosheng Yan ${ }^{5^{*}}$
}

\begin{abstract}
Background: Considerable controversy exists regarding the association between dietary calcium intake and risk of mortality from cardiovascular disease and all causes. Therefore, we performed a meta-analysis of prospective cohort studies to examine the controversy.

Methods: We identified relevant studies by searching MEDLINE, Embase, and the Cochrane Library databases between 1 September 2013 and 30 December 2013. Reference lists of relevant articles were also reviewed. Observational prospective studies that reported relative risks and $95 \%$ confidence intervals for the association of calcium intake with cardiovascular and all-cause mortality were eligible. Study-specific relative risks were pooled using a random-effects model.
\end{abstract}

Results: In this meta-analysis, 11 prospective studies with 12 independent cohorts, involving 757,304 participants, were eligible. There was evidence of a non-linear association between dietary calcium intake and risk of mortality from cardiovascular disease ( $P$ for non-linearity $<0.01$ ) and all causes ( $P$ for non-linearity $<0.01$ ). A dose-response analysis showed a U-shaped relationship between dietary calcium intake and cardiovascular mortality. Intakes that were lower and higher than around $800 \mathrm{mg} /$ day were gradually associated with a higher risk of cardiovascular mortality. For all-cause mortality, we also observed a threshold effect at intakes around $900 \mathrm{mg} /$ day. The risk of all-cause mortality did not decrease further at intakes above $900 \mathrm{mg} /$ day.

Conclusions: This meta-analysis of prospective cohort studies suggests that dietary calcium intake is associated with cardiovascular mortality in a U-shaped manner and that high dietary calcium intake ( $>900 \mathrm{mg} /$ day) is not associated with a decreased risk of all-cause mortality.

Keywords: Calcium, Cardiovascular disease, Cohort, Meta-analysis, Mortality

\section{Background}

Calcium is one of the most common and abundant minerals in the body and has many critical biologic functions. The body tightly controls circulating levels of calcium, usually maintaining a constant range of 1.0 to $1.2 \mathrm{mmol} / \mathrm{L}$ [1]. Increasing calcium intake has been recommended by many healthcare professionals because of its proposed benefit for

\footnotetext{
* Correspondence: drwbao@hotmail.com; 254251509@qq.com

${ }^{2}$ Department of Nutrition and Food Hygiene, School of Public Health, Tongji Medical College, Huazhong University of Science and Technology, 13 Hangkong Road, Wuhan 430030, China

${ }^{5}$ Guangdong Provincial Key Laboratory of Occupational Disease Prevention and Treatment, Guangdong Provincial Hospital for Occupational Disease Prevention and Treatment, 68 Haikang Road, Guangzhou 510300, China Full list of author information is available at the end of the article
}

bone health. Consequently, more than $50 \%$ of older men and almost $70 \%$ of older women in the US are regular users of calcium supplements [2,3].

The health effects of calcium intake on non-skeletal outcomes, including cardiovascular and all-cause mortality, have received growing attention. Some prospective studies found an inverse association between dietary calcium intake and mortality from ischemic heart disease or cardiovascular disease (CVD) [4,5]. By contrast, several recent re-analyses of randomized trials showed that calcium supplements are associated with a higher risk of both ischemic heart disease and stroke, which are two major causes of cardiovascular mortality [6-8]. Thus, the current evidence for an association between calcium intake 
and risk of cardiovascular and all-cause mortality remains insufficient and controversial. Differences in calcium intake doses, which were higher in the trials, may have led to the differences between the observational studies and randomized trials.

Therefore, to evaluate whether the association between calcium intake and risk of mortality from CVD and all causes varies by levels of calcium intake, we conducted a dose-response meta-analysis of prospective cohort studies.

\section{Methods}

\section{Search strategy}

We followed the Meta-analysis of Observational Studies in Epidemiology [9] for conducting and reporting the present study (Additional file 1). We carried out a metaanalysis of prospective cohort studies that evaluated the association between dietary calcium intake and risk of mortality from CVD and all causes.

We systematically searched databases, including MEDLINE (from 1950), Embase (from 1980), and the Cochrane Library (from 1960), between 1 September 2013 and 30 December 2013 (last date searched). The computer-based searches included the key words 'calcium intake', 'calcium supplements', 'calcium supplementation', 'cardiovascular mortality', 'all-cause mortality', 'cause of death', 'cardiovascular diseases', 'coronary heart disease', 'ischemic heart disease','coronary artery disease','myocardial infarction', 'stroke', 'prospective studies', and 'follow-up studies'. No language restrictions were imposed on publications. Furthermore, we identified additional articles by manually searching the reference lists of pertinent articles and recent reviews.

\section{Study selection}

To be included, studies had to be prospective cohort studies that reported relative risks (RRs) with 95\% confidence intervals (CIs) for the association between dietary calcium intake and mortality from CVD and all causes. We excluded studies with ecological, case-control, or cross-sectional designs; studies with no adjustment for potential confounders; and studies that did not report RRs or hazard ratios and corresponding 95\% CIs.

\section{Data extraction and quality assessment}

Data extraction was conducted using a standardized data collection form. The primary exposure variable was dietary calcium intake, which was estimated from foods only, but we also examined supplemental calcium. Outcomes of interest in this study were mortality from CVD and mortality from all causes. All outcomes were classified based on the World Health Organization's International Classification of Disease criteria. Two authors (JL and YO) independently selected studies and performed the data extraction. We recorded the following characteristics for each identified paper: first author, publication year, cohort name, geographical location, sample size of the cohort and number of outcomes, follow-up (years), age at entry, sex, assessment method of dietary calcium intake, ascertainment of outcomes, variables that entered into the multivariable model as potential confounders, and RRs and the associated measure of variance for all categories of dietary calcium intake. Study quality was evaluated by using the Newcastle-Ottawa quality assessment scale [10]. The system allowed a total score of 0 to 9 points ( 9 represented the highest quality).

To perform a dose-response meta-analysis, we assigned the median level of calcium intake in each category to the corresponding RR of that category for each study. If medians were not reported, we used the mean level of calcium intake in each category. If the highest category of the studies was open-ended, the difference from the lowest range to the median was considered equivalent to the same difference in the closest adjacent category.

\section{Data synthesis and analysis}

We used the results of the original studies from multivariable models with the most complete adjustment for potential confounders. We utilized a random-effects model to account for inter-study variation and to provide a more conservative effect than a fixed-effects model. Between-study heterogeneity was assessed using the Cochran's Q test (significance level at $P<0.10$ ) [11]. $I^{2}$ was also evaluated to quantify the proportion of inconsistency across studies [12].

We tested for potential non-linearity in the association between calcium intake and mortality from CVD and all causes using a random-effects dose-response meta-analysis [13]. A potential curvilinear relationship was assessed using restricted cubic splines with three knots at fixed percentiles $(10 \%, 50 \%$, and $90 \%)$ of the distribution [14]. We first estimated a restricted cubic spline model with a generalized least-squares regression taking into account the correlation within each set of published RRs [13-15]. We then pooled the study-specific estimates using the restricted maximum likelihood method [16]. A $P$-value for a non-linear relationship was calculated by testing the null hypothesis that the coefficient of the second spline was equal to zero [17].

We used STATA version 12.0 (StataCorp LP, College Station, TX, USA) to analyze the data. Except where otherwise specified, $P<0.05$ was considered statistically significant.

\section{Results}

\section{Literature search}

Overall, the search initially identified 1,894 reports (Figure 1). After excluding duplicates and papers that did not meet the inclusion criteria, we obtained 13 full articles of potentially relevant studies. After full-text reviews, 2 out of the 13 articles were excluded because they reported risk of coronary heart disease or stroke rather than 
mortality [18,19]. Finally, 11 articles [5,18,20-28] with 12 independent cohorts fulfilled our inclusion criteria. Dai et al.'s report [21] included data from two independent cohorts.

\section{Study characteristics}

Table 1 illustrates the characteristics of the 11 included studies, all of which had prospective cohort design. Of these, nine prospective studies $[5,18,20-26]$ reported data on the relation of dietary calcium intake and total CVD mortality, and six studies [5,20-22,26,28] on all-cause mortality. Six prospective studies [20,22-25,27] examined the relationship between supplemental calcium intake and cardiovascular mortality. One study consisted entirely of men, two of women only, and eight of both men and women. Study length ranged from 5.5 years to 28 years. Three studies were conducted in the US, one in Canada, three in China, and four in Europe.

One study used one week food frequency recall to measure dietary calcium intake, and all other studies used food frequency questionnaires. All studies provided the estimates adjusted for age. Most of the studies also controlled for energy intake and smoking $(\mathrm{n}=10)$, alcohol consumption and body mass index $(n=9)$, physical activity $(n=8)$, and other dietary variables or nutrients $(n=7)$. No study scored the highest level of quality (maximum 9), with five of the nine studies scoring 8 , five scoring 7 , and one scoring 6 .

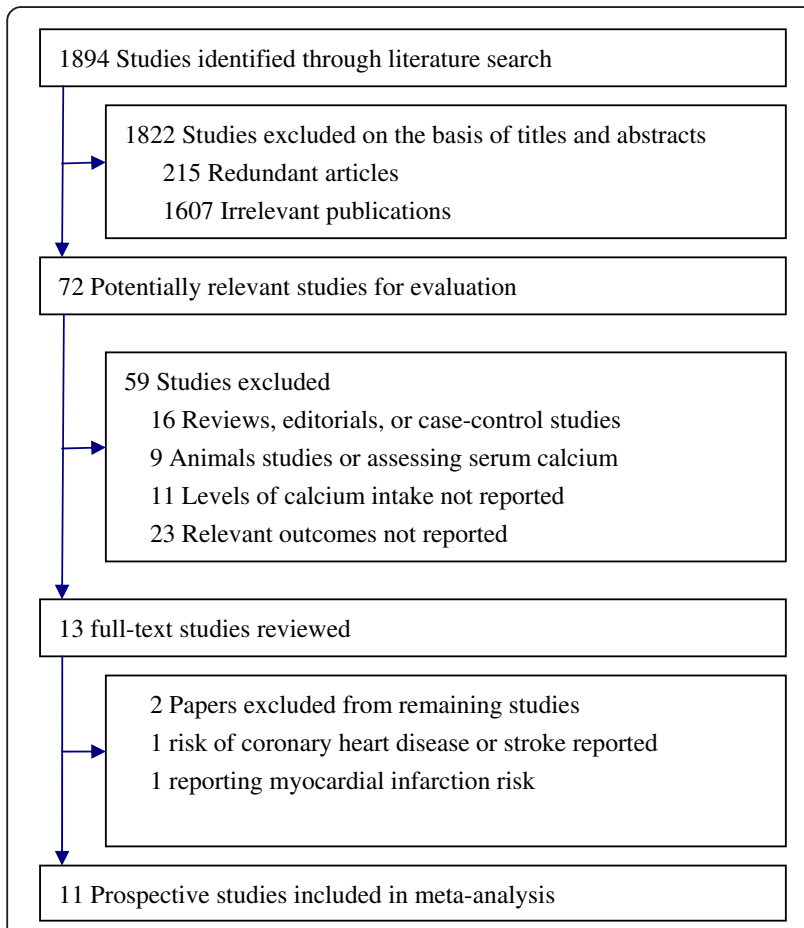

Figure 1 Flow chart of study selection. Shows literature search for prospective cohort studies of calcium intake in relation to cardiovascular and all-cause mortality.

\section{Dietary calcium intake and cardiovascular mortality}

Cardiovascular mortality was evaluated in nine prospective cohort studies [5,18,20-26] comprising 709,499 subjects and at least 21,457 deaths from CVD. The exact number of deaths is unknown because one study [26] did not report the number of deaths.

The pooled RR of cardiovascular mortality comparing the highest and lowest level of dietary calcium intake was 0.97 (95\% CI: 0.89 to $1.07 ; P=0.60$ ), with no heterogeneity among the studies $\left(I^{2}=18.8 \% ; P=0.28\right)$ (Figure 2$)$. The Begg rank correlation test and Egger linear regression test indicated no significant publication bias (Begg, $P=0.75$; Egger, $P=0.11$ ).

The dose-response analysis revealeda non-linear association $(P<0.01)$. The tendency of a U-shaped association between dietary calcium intake and deaths from CVD was visualized by the pattern of the spline curves in Figure 3. At intakes below $800 \mathrm{mg} /$ day, there was a higher risk of cardiovascular mortality with lower intake of dietary calcium. Intakes around $800 \mathrm{mg} /$ day conferred the lowest risk of cardiovascular mortality. By contrast, at intakes above $800 \mathrm{mg} /$ day, a higher intake was progressively associated with a higher risk of cardiovascular mortality. Compared to individuals with $800 \mathrm{mg} /$ day of dietary calcium intake, the predicted RRs for cardiovascular mortality were 1.08 (95\% CI: 0.98 to 1.20 ) for individuals with $500 \mathrm{mg} /$ day of calcium intake, 1.01 (95\% CI: 0.98 to 1.04 ) for 1,000 mg/day, 1.05 (95\% CI: 1.01 to 1.09 ) for $1,200 \mathrm{mg} /$ day, and 1.10 (95\% CI: 1.02 to 1.18 ) for $1,400 \mathrm{mg} /$ day.

\section{Dietary calcium intake and all-cause mortality}

All-cause mortality was investigated in six studies [5,20-22,26,28] involving a total of 225,189 subjects and at least 21,055 deaths from all causes. One study [28] was not included in our analysis because it reported only one intake level of calcium. The summary relative risks of all-cause mortality comparing the highest and lowest level of dietary calcium intake was 0.83 (95\% CI: 0.70 to $1.00 ; P=0.05$ ), with significant heterogeneity among the studies $\left(I^{2}=74.9 \% ; P=0.003\right.$; Additional file 2: Figure S1). No significant publication bias was observed (Begg test, $P=0.46$; Egger test, $P=0.34$ ). We found evidence of a non-linear association $(P<0.01$; Additional file 2: Figure S2). We found a threshold effect at intakes of about $900 \mathrm{mg} /$ day. Compared to intakes of $900 \mathrm{mg} /$ day, a lower intake was gradually associated with a higher risk of all-cause mortality. At intakes above $900 \mathrm{mg} /$ day, risk of all-cause mortality did not reduced with the increase of dietary calcium intake.

Supplemental calcium intake and cardiovascular mortality Six studies [20,22-25,27] reported the relationship between supplemental calcium intake and cardiovascular mortality 
Table 1 Summary of prospective studies that examined the association between calcium intake and risk of mortality

\begin{tabular}{|c|c|c|c|c|c|c|c|c|}
\hline Study & Country & $\begin{array}{l}\text { Number of } \\
\text { participants }\end{array}$ & $\begin{array}{l}\text { Age } \\
\text { (years) }\end{array}$ & $\begin{array}{l}\text { Endpoints } \\
\text { (Number of cases) }\end{array}$ & $\begin{array}{l}\text { Follow-up period } \\
\text { and person time }{ }^{a}\end{array}$ & Calcium intake (mg/day) & Covariates in fully adjusted model & $\begin{array}{l}\text { Quality } \\
\text { score }\end{array}$ \\
\hline $\begin{array}{l}\text { Chan et al. 2013, a cohort of } \\
\text { older community-dwelling } \\
\text { people [20] }\end{array}$ & China & $\begin{array}{l}3,139 \text { men } \\
\text { and women }\end{array}$ & $\geq 65$ & $\begin{array}{l}\text { CVD mortality } \\
(114) \text {, all-cause } \\
\text { mortality (529) }\end{array}$ & $\begin{array}{l}9.1 \text { years; } 27,289 \\
\text { person years }\end{array}$ & $\begin{array}{l}\text { Dietary calcium: } \mathrm{M}:<458,458 \\
\text { to } 584,584 \text { to } 762,>762 ; \mathrm{W}: \\
<417,417 \text { to } 529,529 \text { to } 688, \\
>688 ; \text { Calcium supplement } \\
\text { users versus nonusers }\end{array}$ & $\begin{array}{l}\text { Age, smoking, sex, BMI, PASE, alcohol, } \\
\text { education, history of diabetes and } \\
\text { hypertension, energy intake, percentage } \\
\text { of energy from total fat, percentage of } \\
\text { energy from saturated fat, and calcium } \\
\text { supplemental use }\end{array}$ & 7 \\
\hline Dai et al. 2013, SWHS [21] & China & 73,232 women & 40 to 70 & $\begin{array}{l}\text { CVD mortality } \\
(1,147) \text {, all-cause } \\
\text { mortality }(3,806)\end{array}$ & $\begin{array}{l}11 \text { years; } 806,549 \\
\text { person years }\end{array}$ & $\begin{array}{l}\text { Dietary calcium: }<408,408 \\
\text { to } 600, \geq 600\end{array}$ & $\begin{array}{l}\text { Age, smoking, sex, BMI, physical activity, } \\
\text { alcohol, education, marriage status, tea } \\
\text { drinking, use of ginseng, use of calcium } \\
\text { supplement, use of multivitamin, intakes } \\
\text { of total energy, SFA, phosphorus, fiber, } \\
\text { retinol, vitamin E, folic acid, sodium, } \\
\text { potassium and zinc }\end{array}$ & 7 \\
\hline Dai et al. 2013, SMHS [21] & China & 61,414 men & 40 to 74 & $\begin{array}{l}\text { CVD mortality } \\
(800) \text {, all-cause } \\
\text { mortality }(2,418)\end{array}$ & $\begin{array}{l}5.5 \text { years; } 336,984 \\
\text { person years }\end{array}$ & $\begin{array}{l}\text { Dietary calcium: }<408,408 \\
\text { to } 600, \geq 600\end{array}$ & Same as above & 7 \\
\hline
\end{tabular}

Langsetmo et al. 2013, Canada $\quad 9,033$ men $\quad \geq 25 \quad$ All-cause mortality 10 years; 77,558 CaMos [28] and women

$$
(1,160)
$$

person years
Age, study center, education, BMl, health 7 status, smoking, alcohol, physical activity, sun exposure, self-reported comorbidity (in men and women: hypertension, heart disease, stroke, type 2 diabetes, COPD, and kidney stones; in women only: osteoporosis, thyroid disease, IBD, breast cancer, and uterine cancer; in men only: prostate cancer), and medication (aspirin use or other NSAIDs)

19 years; $1,094,880$ Dietary calcium: $<600,600$ to Age, smoking, BMl, physical activity, total 8 999, 1,000 to 1,399, $\geq 1,400$; $\quad$ energy and vitamin D intake, a healthy any calcium users versus dietary pattern, height, living alone, nonusers education, use of calcium-containing supplements, and Charlson's comorbidity index person years

Dietary calcium: M: 478, 616,

18 years; 243,227 person years and women $(1,870)$ $739,898,1,247$ (medians); W: $408,532,648,798,1,101$ (medians); Calcium

supplement: $0,<400,400$ to $1,000, \geq 1,000$

Dietary calcium: $<500,500$ to $1,000,1,000$ to $1,300,>1,300$

Age, BMl, smoking, race, physical activity, 8 alcohol, education, marital status, health status, supplemental calcium intake, fruit and vegetable intake, red meat intake, whole grain intake, total fat intake, and total caloric intake, and use of menopausal hormone therapy (for women)

Age, smoking, BMI, sex, race/ethnicity, physical activity, alcohol, poverty to income ratio, comorbidity index, serum vitamin $D$, vigorous and total energy intake

Dietary calcium: 513, 675, Age, sex, smoking, BMl, physical activity, 7 820, 1,130 (medians); Calcium alcohol, education, history of diabetes, use of calcium supplements, and intakes 
Table 1 Summary of prospective studies that examined the association between calcium intake and risk of mortality (Continued)

\begin{tabular}{|c|c|c|c|c|c|c|c|c|}
\hline & & & & & & $\begin{array}{l}\text { only users versus nonusers of } \\
\text { supplements }\end{array}$ & $\begin{array}{l}\text { of total energy, vitamin D, SFAs and } \\
\text { total protein }\end{array}$ & \\
\hline Mursu et al. 2011, IWHS [27] & USA & 38,772 women & 5 to 69 & $\begin{array}{l}\text { CVD mortality } \\
(3,319)\end{array}$ & $\begin{array}{l}11 \text { years; } 228,085 \\
\text { person years }\end{array}$ & $\begin{array}{l}\text { Calcium supplement use } \\
\text { (yes/no) }\end{array}$ & $\begin{array}{l}\text { Age, education, place of residence, } \\
\text { diabetes mellitus, high blood pressure, } \\
\text { BMl, waist to hip ratio, hormone } \\
\text { replacement therapy, physical activity, } \\
\text { smoking, and intake of energy, alcohol, } \\
\text { saturated fatty acids, whole grain } \\
\text { products, and fruits, and vegetables }\end{array}$ & 7 \\
\hline Kaluza et al. 2010, COSM [5] & Sweden & 23,366 men & 4 to 79 & $\begin{array}{l}\text { CVD mortality } \\
(819) \text {, all-cause } \\
\text { mortality }(2,358)\end{array}$ & $\begin{array}{l}10 \text { years; } 224,206 \\
\text { person years }\end{array}$ & $\begin{array}{l}\text { Dietary calcium: <1230, } 1230 \\
\text { to } 1598, \geq 1599\end{array}$ & $\begin{array}{l}\text { Age, smoking, physical activity, alcohol, } \\
\text { marital status, education, health status, } \\
\text { waist-to-hip ratio, energy-adjusted } \\
\text { dietary fiber, SFA, vitamin D, and } \\
\text { phosphorus intake }\end{array}$ & 7 \\
\hline $\begin{array}{l}\text { Umesawa et al. 2006, } \\
\text { JACC [18] }\end{array}$ & Japan & $\begin{array}{l}21,068 \text { men } \\
\text { and } 32,319 \\
\text { women }\end{array}$ & 4 to 79 & CVD mortality (800) & $\begin{array}{l}9.6 \text { years; } 515,029 \\
\text { person years }\end{array}$ & $\begin{array}{l}\text { Dietary calcium: M: 250, 363, } \\
\text { 449, 536, } 665 \text { (medians); W: } \\
\text { 266, 379, 462, 545, 667 } \\
\text { (medians) }\end{array}$ & $\begin{array}{l}\text { Age, smoking, BMl, alcohol, hypertension, } \\
\text { diabetes, and intakes of total energy }\end{array}$ & 6 \\
\hline $\begin{array}{l}\text { Van der Vijver et al. 1992, } \\
\text { Civil Servants [26] }\end{array}$ & Netherlands & $\begin{array}{l}1,340 \text { men } \\
\text { and } 1,265 \\
\text { women }\end{array}$ & 4 to 65 & $\begin{array}{l}\text { CVD mortality (NA), } \\
\text { all-cause mortality } \\
\text { (NA) }\end{array}$ & $\begin{array}{l}28 \text { years; } 72,940 \\
\text { person years }\end{array}$ & $\begin{array}{l}\text { Dietary calcium: } \mathrm{M}: \leq 585, \\
585 \text { to } 1245,>1245 ; \mathrm{W}: \leq 445 \\
445 \text { to } 850,>850\end{array}$ & $\begin{array}{l}\text { Age, energy intake, systolic blood } \\
\text { pressure }\end{array}$ & 5 \\
\hline
\end{tabular}

a Person time estimated by multiplying number of participants by average follow-up time. BMI, body mass index; CaMos, Canadian Multicentre Osteoporosis Study; COPD, chronic obstructive pulmonary disease; COSM, Cohort of Swedish Men; CVD, cardiovascular disease; IBD, inflammatory bowel disease; IWHS, lowa Women's Health Study; JACC, Japan Collaborative Cohort study; M, men; NA, not available; NHANES III, Third National Cohort of Swedish Men; CVD, cardiovascular disease; IBD, inflammatory bowel disease; IWHS, lowa Women's Health Study; JACC, Japan Collaborative Cohort study; M, men; NA, not available; NHANES III, Third National
Health and Nutrition Examination Survey; NIH-AARP, National Institutes of Health - AARP Diet and Health Study; NSAIDs, aspirin use or other non-steroidal anti-inflammatory drugs; PASE, Physical Activity Scale for the Health and Nutrition Examination Survey; NIH-AARP, National Institutes of Health - AARP Diet and Health Study; NSAIDs, aspin
Elderly; SFA, saturated fatty acid; SMHS, Shanghai Men's Health Study; SWHS, Shanghai Women's Health Study; W, women. 


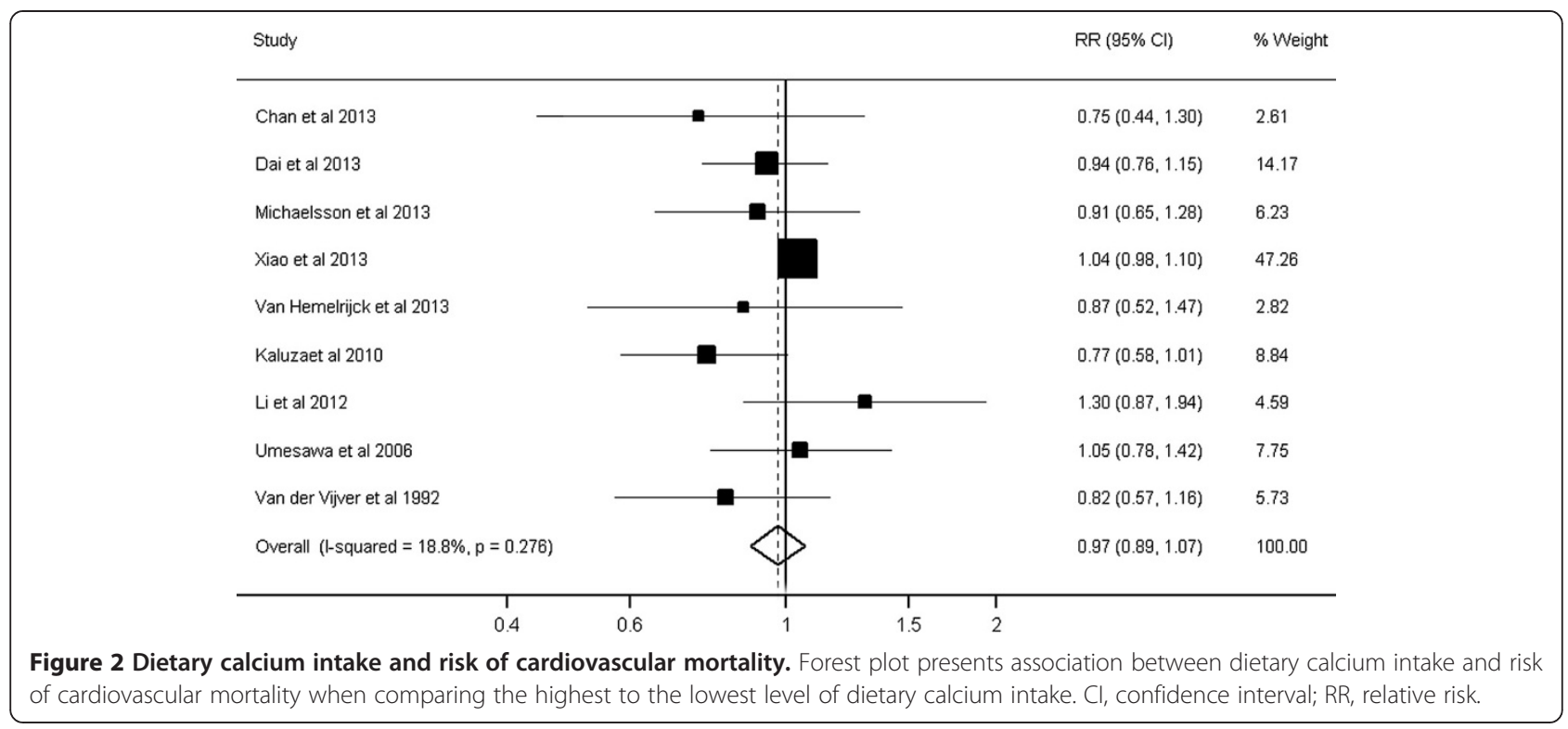

(Table 1). None of the studies found a statistically significant association. Use of calcium supplements was not significantly associated with cardiovascular mortality in comparison with non-use of any supplements $(\mathrm{RR}=0.96 ; 95 \% \mathrm{CI}$ : 0.82 to $1.13 ; P=0.66$; Additional file 2 : Figure S3).

\section{Subgroup and sensitivity analyses}

To test the robustness of the results and investigate the sources of between-study heterogeneity, we conducted subgroup analyses. Table 2 presents the different subgroup analyses of studies on cardiovascular and all-cause mortality. The associations between dietary calcium intake and

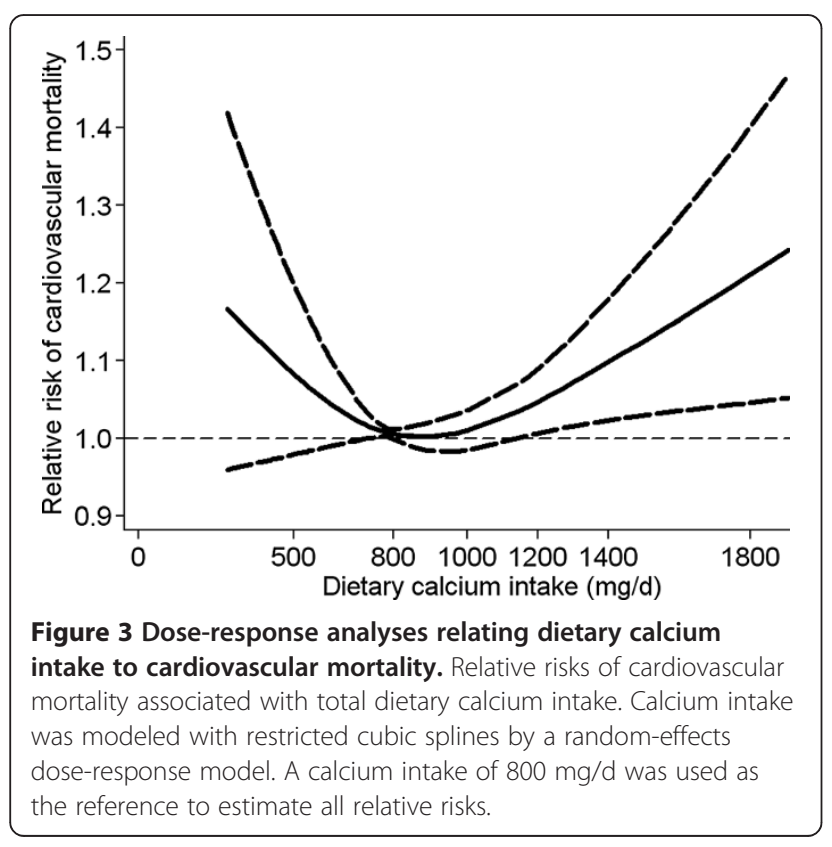

risk of cardiovascular and all-cause mortality did not differ substantially by study location, sex, or whether vitamin D status was controlled for in models.

For all-cause mortality, subgroup analyses showed that dietary calcium intakes were not significantly associated with an increased mortality risk in studies with more than 10 years of follow-up, but not in studies with less than 10 years.

We also performed a sensitivity analysis. Exclusion of one study [20] that enrolled people aged over 65 years yielded similar results for cardiovascular mortality ( RR $=1.00 ; 95 \% \mathrm{CI}: 0.94$ to $1.07 ; P=0.90)$ or all-cause mortality ( $R R=0.89 ; 95 \%$ CI: 0.76 to $1.05 ; P=0.18)$.

\section{Discussion}

This meta-analysis of prospective studies indicates a U-shaped relationship between dietary calcium intake and cardiovascular mortality. Compared with intakes of $800 \mathrm{mg} /$ day, both lower and higher intakes were gradually associated with a higher risk of cardiovascular mortality. For all-cause mortality, we also observed a threshold effect at intakes about $900 \mathrm{mg} /$ day. Intakes above $900 \mathrm{mg} /$ day were not associated with a decrease in risk of all-cause mortality.

Vitamin D, directly or indirectly, enhances renal conservation of the absorbed calcium and intestinal absorption of calcium [29]. Some studies have noted that serum 25-hydroxyvitamin D levels, the major circulating metabolite of vitamin $\mathrm{D}$, are inversely correlated with CVD incidence rates [30,31]. The co-administration of calcium with vitamin D may reduce the adverse effect of dietary calcium. Therefore, to explore a potential source of heterogeneity in our results, we also considered vitamin D status associated with dietary calcium intake. However, 
Table 2 Stratified analysis on the associations of dietary calcium intake and mortality from cardiovascular disease and all causes

\begin{tabular}{|c|c|c|c|c|c|c|c|c|}
\hline & \multicolumn{5}{|c|}{ Cardiovascular mortality } & \multicolumn{3}{|l|}{ All-cause mortality } \\
\hline & Number & RR $(95 \% \mathrm{Cl})$ & $P^{a}$ & $I^{2}(\%)$ & Number & RR $(95 \% \mathrm{Cl})$ & $P^{\mathrm{a}}$ & $\overline{I^{2}(\%)}$ \\
\hline \multicolumn{9}{|l|}{ Location: } \\
\hline United States & 2 & 1.04 (0.98 to 1.10$)$ & 0.50 & 0.0 & - & - & - & - \\
\hline Europe & 4 & 0.90 (0.73 to 1.12$)$ & 0.20 & 36.1 & 3 & 0.85 (0.68 to 1.06$)$ & 0.08 & 61.1 \\
\hline Asia & 3 & 0.95 (0.81 to 1.12$)$ & 0.56 & 0.0 & 2 & 0.80 (0.52 to 1.23$)$ & 0.002 & 89.9 \\
\hline \multicolumn{9}{|l|}{ Sex: } \\
\hline Male and female & 3 & 0.99 (0.70 to 1.39$)$ & 0.22 & 33.3 & 2 & 0.66 (0.53 to 0.82$)$ & 0.45 & 0.0 \\
\hline Male & 5 & 0.88 (0.74 to 1.06$)$ & 0.06 & 55.2 & 2 & 0.91 (0.74 to 1.11) & 0.14 & 54.7 \\
\hline Female & 5 & 1.04 (0.95 to 1.13 ) & 0.90 & 0.0 & 2 & 0.90 (0.63 to 1.29$)$ & 0.001 & 90.6 \\
\hline \multicolumn{9}{|l|}{ Follow-up time: } \\
\hline$>10$ years & 6 & 1.03 (0.97 to 1.08 ) & 0.46 & 0.0 & 3 & 0.98 (0.89 to 1.07$)$ & 0.56 & 0.0 \\
\hline$\leq 10$ years & 3 & 0.87 (0.70 to 1.08 ) & 0.28 & 21.5 & 2 & 0.71 (0.60 to 0.83$)$ & 0.26 & 22.0 \\
\hline \multicolumn{9}{|c|}{ Controlling for vitamin D status in models: } \\
\hline Yes & 4 & $0.92(0.74$ to 1.15$)$ & 0.22 & 32.7 & 2 & 0.87 (0.65 to 1.16$)$ & 0.03 & 80.0 \\
\hline No & 5 & 1.02 (0.97 to 1.08$)$ & 0.44 & 0.0 & 3 & 0.79 (0.57 to 1.10$)$ & 0.006 & 80.7 \\
\hline
\end{tabular}

${ }^{\mathrm{a} P}$ for heterogeneity. $\mathrm{Cl}$, confidence interval; $\mathrm{RR}$, relative risk.

subgroup analyses showed that dietary calcium intakes were not significantly associated with all-cause mortality in studies that adjusted for vitamin D status.

Heterogeneity could also be caused by differences in dietary magnesium intake. None of the included studies adjusted for dietary magnesium intake. However, some studies showed that dietary magnesium intake is associated with reduced mortality from CVD [32,33]. It is possible that magnesium counters the effects of calcium on risk of CVD. Furthermore, some studies also suggest that balance between calcium and magnesium may help prevent CVD $[21,34]$.

Another possible explanation for the differences between the studies might be the effects of sex and age on the risks of CVD and mortality rates with respect to dietary calcium or supplemental calcium intake. Supplemental calcium intake is associated with an elevated CVD mortality in men but not in women [23]. A recent study by Paik et al. [35] found that supplement calcium intake did not increase CVD risk in women. Dietary supplement use is more common in women than in men [36]. Additionally, male users of calcium supplements may start taking calcium supplements at an older age [23]. However, in the present study, sensitivity analyses by excluding one study in older people showed similar results.

Women with a calcium intake below $600 \mathrm{mg} /$ day had a higher risk of stroke in the Nurses' Health Study [37]. There was higher mortality from ischemic heart disease with a total calcium intake below $700 \mathrm{mg}$ /day in the Iowa Women's Health Study cohort [4]. An intake below about $500 \mathrm{mg} /$ day was also associated with higher rate of stroke in Japanese people with habitual low calcium intake [18]. In our study, at intakes below $800 \mathrm{mg} /$ day, there was a higher risk of cardiovascular mortality with lower intake of calcium. Our results also indicated that intakes of about $800 \mathrm{mg} /$ day, which corresponds to the recommended daily intake for Swedish women aged more than 50 years [38], conferred the lowest risk of cardiovascular mortality. Moreover, a recent meta-analysis by Larsson et al. [39] showed that high dietary calcium intake is related to a lower risk of stroke in populations with low to moderate calcium intakes. Therefore, increased dietary calcium intake may be associated with reduced cardiovascular mortality risk at low to moderate calcium intakes.

In addition, our study showed that, in comparison with intakes of $800 \mathrm{mg} /$ day, a higher intake was associated with increased risk of cardiovascular mortality. In a re-analysis of randomized trials, a higher rate of myocardial infarction was observed for calcium supplementation [40]. The results from a meta-analysis of randomized trials of calcium supplements also indicated a higher risk of cardiovascular events in women with intake levels of dietary calcium above $800 \mathrm{mg} /$ day, but not in women with lower intake levels [6]. Thus, it is likely that increasing dietary calcium intake may increase risk of cardiovascular mortality in individuals who already consume adequate amounts of calcium.

Our results are concordant with findings from a recent review [41] in which calcium intake was not associated with risk of CVD when comparing the highest and lowest intake levels. However, this study [41] did not evaluate the dose-response relationship of dietary calcium intake and CVD. In the current study, dose-response analysis showed 
that the association between dietary calcium intake and cardiovascular mortality was U-shaped. The null findings to date for comparing the highest and lowest calcium intake categories likely related to the non-linear association.

Moreover, a recent meta-analysis [42] showed that higher calcium intake may be associated with a reduction in risk of colorectal cancer beyond 1,000 mg/day. There could therefore be beneficial effects of calcium intake on risk of some cancers, such as colorectal. However, a meta-analysis of randomized controlled trials suggested no effect of calcium on the risk of total cancer [43]. In the present study, a high calcium intake ( $>900 \mathrm{mg} /$ day) was not associated with a decreased rate of all-cause mortality. We found that, for all-cause mortality, dietary calcium intakes were not significantly associated with an increased mortality risk in studies with more than 10 years of follow-up, but not in studies with less than 10 years. It is possible that the follow-up periods in these studies were too short to identify the true associations with mortality. In fact, longer induction periods were observed for cancers than for CVD.

For calcium supplement use, a previous review [44] suggested that the evidence regarding the relationship between calcium supplement use and increased CVD risk is insufficient. A study by Radford et al. [45] showed that the effects of calcium supplements on cardiovascular risk did not differ across varying patient subpopulations, such as younger people and those with low dietary calcium intake. The present study also found no evidence that calcium supplements increased the risk of cardiovascular mortality. Thus, more longitudinal studies are needed to confirm or refute the results of our study.

Calcium is a vital electrolyte and part of the etiological pathway of CVD. Nevertheless, calcium has mainly been explored in relation to bone health. As a concern in osteoporosis management, it is only recently that the cardiovascular safety of calcium supplementation has been queried [46]. Calcium blood concentrations are under tight homeostatic control by the calciotropic hormones [47]. Alterations in calcium homeostasis caused by diets that are low or very high in calcium can alter blood levels of calcium and calciotropic hormones [48]. Calcium intakes that are too low may cause mortality or CVD risk through pathways that affect blood pressure [49,50], insulin secretion and sensitivity [51-53], and blood cholesterol concentrations [53]. Likewise, excessive amounts of calcium may also exert a harmful effect on cardiovascular health by inducing a hypercoagulable state $[54,55]$. Many studies show that high levels of circulating fibroblast growth factor-23 are associated with higher risk of cardiovascular events and all-cause mortality [56-58], whereas calciumenriched meals can raise serum levels of fibroblast growth factor-23 [59]. High calcium intake may also increase risk of mortality associated with vascular and soft tissue calcification $[60,61]$ and effects on arterial stiffness $[62,63]$.
We used estimates from the fully adjusted models from all included studies in our analyses to reduce the potential for confounding. We conducted the dose-response metaanalysis to evaluate non-linear relationships, which helped to test the shape of these possible associations. Some limitations of this meta-analysis should be addressed. All included studies were observational in nature. The results may be subject to residual confounding or unmeasured factors. Moreover, dietary calcium intake was measured at baseline in the included studies. During the long follow-up, participants may have changed their diets, including changing their dietary calcium intakes. Therefore, we were not able to evaluate change in dietary calcium intake during follow-up. Besides, calcium intake levels were assessed by food frequency questionnaires in most studies. Measurement errors of calcium intake were possible. However, the prospective nature of the included studies could have led to an underestimation of the real association and could not explain the positive associations we observed in this study.

Our results, together with previous studies, suggest that increasing dietary calcium intake is associated with decreased mortality risk at low to moderate calcium intakes, whereas it is not associated with a decreased risk of mortality at high calcium intakes. Thus, intake recommendations for calcium should consider individual characteristics and should focus on people with low intake levels of calcium, rather than increasing the intake of those with adequate amounts of calcium.

\section{Conclusions}

This meta-analysis suggests a U-shaped relationship between dietary calcium intake and risk of cardiovascular mortality. A high calcium intake ( $>900 \mathrm{mg} /$ day) was not associated with a reduced risk of all-cause mortality.

\section{Additional files}

\section{Additional file 1: Meta-analysis of Observational Studies in Epidemiology Checklist.}

Additional file 2: Figure S1. Association between dietary calcium intake and risk of all-cause mortality when comparing the highest to lowest level of dietary calcium intake. Figure S2. Dose-response analyses relating dietary calcium intake to all-cause mortality. RRs of all-cause mortality associated with dietary calcium intake. Calcium intake was modeled with restricted cubic splines by a random-effects dose-response model. A calcium intake of $500 \mathrm{mg} / \mathrm{d}$ was used as the reference to estimate all RRs. Figure S3. Association between calcium supplement use and risk of cardiovascular mortality when comparing users of calcium supplements with non-users.

Abbreviations

$\mathrm{Cl}$ : confidence interval; CVD: cardiovascular disease; RR: relative risk.

\section{Competing interests}

The authors declare that they have no competing interests. 


\section{Authors' contributions}

$X W, Y O, J L, G Z$, and WB: developed the study concept and designed the study; XW, YO, MSY, and JL conducted data extraction and validity assessment, and statistical analysis; XW: wrote the manuscript, and reviewed and edited the manuscript; XW, HXC, MSY, and WB: reviewed and edited the manuscript. All authors read and approved the final manuscript.

\section{Acknowledgments}

This work was supported by grants from the National Natural Science Foundation (NSFC 81370966) of China. The sponsors played no role in the design of the study; in the collection, analysis, or interpretation of the data; or in the preparation or approval of the manuscript.

\section{Author details}

'Department of Maternal and Child Health Care, School of Public Health, Shandong University, Jinan, China. ${ }^{2}$ Department of Nutrition and Food Hygiene, School of Public Health, Tongji Medical College, Huazhong University of Science and Technology, 13 Hangkong Road, Wuhan 430030, China. ${ }^{3}$ Institute of Biomedicine, Taihe Hospital, Hubei University of Medicine, Shiyan, Hubei Province, China. ${ }^{4}$ Department of Cardiovascular Sciences, Shandong Provincial Hospital affiliated to Shandong University, Jinan, China ${ }^{5}$ Guangdong Provincial Key Laboratory of Occupational Disease Prevention and Treatment, Guangdong Provincial Hospital for Occupational Disease Prevention and Treatment, 68 Haikang Road, Guangzhou 510300, China.

Received: 22 April 2014 Accepted: 20 August 2014

Published online: 25 September 2014

\section{References}

1. Ross AC, Taylor CL, Yaktine AL, del Valle HB: Dietary Reference Intakes for Calcium and Vitamin D. National Academies Press; 2010.

2. Mangano KM, Walsh SJ, Insogna KL, Kenny AM, Kerstetter JE: Calcium intake in the United States from dietary and supplemental sources across adult age groups: new estimates from the National Health and Nutrition Examination Survey 2003-2006. J Am Diet Assoc 2011, 111:687-695.

3. Bailey RL, Dodd KW, Goldman JA, Gahche JJ, Dwyer JT, Moshfegh AJ, Sempos CT, Picciano MF: Estimation of total usual calcium and vitamin D intakes in the United States. J Nutr 2010, 140:817-822.

4. Bostick RM, Kushi LH, Wu Y, Meyer KA, Sellers TA, Folsom AR: Relation of calcium, vitamin $D$, and dairy food intake to ischemic heart disease mortality among postmenopausal women. Am J Epidemiol 1999 149:151-161.

5. Kaluza J, Orsini N, Levitan EB, Brzozowska A, Roszkowski W, Wolk A: Dietary calcium and magnesium intake and mortality: a prospective study of men. Am J Epidemiol 2010, 171:801-807.

6. Bolland MJ, Avenell A, Baron JA, Grey A, MacLennan GS, Gamble GD, Reid IR: Effect of calcium supplements on risk of myocardial infarction and cardiovascular events: meta-analysis. BMJ 2010, 341:c3691.

7. Bolland MJ, Barber PA, Doughty RN, Mason B, Horne A, Ames R, Gamble GD, Grey A, Reid IR: Vascular events in healthy older women receiving calcium supplementation: randomised controlled trial. BMJ 2008, 336:262-266.

8. Bolland MJ, Grey A, Avenell A, Gamble GD, Reid IR: Calcium supplements with or without vitamin D and risk of cardiovascular events: reanalysis of the Women's Health Initiative limited access dataset and meta-analysis. BMJ 2011, 342:d2040

9. Stroup DF, Berlin JA, Morton SC, Olkin I, Williamson GD, Rennie D, Moher D, Becker BJ, Sipe TA, Thacker SB: Meta-analysis of observational studies in epidemiology. JAMA 2000, 283:2008-2012.

10. Wells G, Shea B, O'Connell D, Peterson J, Welch V, Losos M, Tugwell P: The Newcastle-Ottawa Scale (NOS) for Assessing the Quality of Nonrandomised Studies in Meta-Analyses. 2000, [http://www.ohri.ca/programs/ clinical_epidemiology/oxford.asp].

11. Hedges LV, Olkin I, Statistiker M: Statistical Methods for Meta-Analysis. Orlando, FL: Academic Press; 1985.

12. Higgins J, Thompson SG, Deeks JJ, Altman DG: Measuring inconsistency in meta-analyses. BMJ 2003, 327:557-560.

13. Greenland S, Longnecker MP: Methods for trend estimation from summarized dose-response data, with applications to meta-analysis. Am J Epidemiol 1992, 135:1301-1309.
14. Orsini N, Li R, Wolk A, Khudyakov P, Spiegelman D: Meta-analysis for linear and nonlinear dose-response relations: examples, an evaluation of approximations, and software. Am J Epidemiol 2012, 175:66-73.

15. Berlin JA, Longnecker MP, Greenland S: Meta-analysis of epidemiologic dose-response data. Epidemiology 1993, 4:218-228.

16. Jackson D, White $\mathbb{R}$, Thompson SG: Extending DerSimonian and Laird's methodology to perform multivariate random effects meta-analyses. Stat Med 2010, 29:1282-1297.

17. Larsson SC, Orsini N: Coffee consumption and risk of stroke: a dose-response meta-analysis of prospective studies. Am J Epidemiol 2011, 174:993-1001.

18. Umesawa M, Iso H, Ishihara J, Saito I, Kokubo Y, Inoue M, Tsugane S: Dietary calcium intake and risks of stroke, its subtypes, and coronary heart disease in Japanese: the JPHC Study Cohort I. Stroke 2008, 39:2449-2456.

19. Marniemi J, Alanen E, Impivaara O, Seppänen R, Hakala P, Rajala T, Rönnemaa T: Dietary and serum vitamins and minerals as predictors of myocardial infarction and stroke in elderly subjects. Nutri Metab Cardiovas 2005, 15:188-197.

20. Chan R, Leung J, Woo J: A Prospective Cohort Study Examining the Associations of Dietary Calcium Intake with All-Cause and Cardiovascular Mortality in Older Chinese Community-Dwelling People. PLoS One 2013, 8:e80895.

21. Dai Q, Shu X, Deng X, Xiang Y, Li H, Yang G, Shrubsole MJ, Ji B, Cai H, Chow $W$ : Modifying effect of calcium/magnesium intake ratio and mortality: a population-based cohort study. BMJ open 2013, 3:e002111.

22. Michaëlsson K, Melhus H, Lemming EW, Wolk A, Byberg L: Long term calcium intake and rates of all cause and cardiovascular mortality: community based prospective longitudinal cohort study. BMJ 2013, 346: $\{228$.

23. Xiao Q, Murphy RA, Houston DK, Harris TB, Chow W-H, Park Y: Dietary and supplemental calcium intake and cardiovascular disease mortality: the National Institutes of Health-AARP Diet and Health Study. JAMA 2013, 173:639-646.

24. Van Hemelrijck M, Michaelsson K, Linseisen J, Rohrmann S: Calcium intake and serum concentration in relation to risk of cardiovascular death in NHANES III. PLoS One 2013, 8:e61037.

25. Li K, Kaaks R, Linseisen J, Rohrmann S: Associations of dietary calcium intake and calcium supplementation with myocardial infarction and stroke risk and overall cardiovascular mortality in the Heidelberg cohort of the European Prospective Investigation into Cancer and Nutrition study (EPIC-Heidelberg). Heart 2012, 98:920-925.

26. Van der Vijver $L$, van der Waal M, Weterings $K$, Dekker J, Schouten E, Kok F: Calcium intake and 28-year cardiovascular and coronary heart disease mortality in Dutch civil servants. Int J Epidemiol 1992, 21:36-39.

27. Mursu J, Robien K, Harnack LJ, Park K, Jacobs DR Jr: Dietary supplement and mortality rate in older women: the lowa Women's Health Study. Arch Intern Med 2011, 171:1625-1633.

28. Langsetmo L, Berger C, Kreiger N, Kovacs CS, Hanley DA, Jamal SA, Whiting SJ, Genest J, Morin SN, Hodsman A: Calcium and vitamin D intake and mortality: results from the Canadian Multicentre Osteoporosis Study (CaMos). J Clin Endocr Metab 2013, 98:3010-3018.

29. Cashman KD: Diet, nutrition, and bone health. J Nutr 2007, 137:2507S-2512S

30. Anderson JL, May HT, Horne BD, Bair TL, Hall NL, Carlquist JF, Lappe DL, Muhlestein JB: Relation of vitamin D deficiency to cardiovascular risk factors, disease status, and incident events in a general healthcare population. Am J Cardiol 2010, 106:963-968.

31. Wang L, Song Y, Manson JE, Pilz S, Marz W, Michaelsson K, Lundqvist A, Jassal SK, Barrett-Connor E, Zhang C, Eaton CB, May HT, Anderson JL, Sesso HD: Circulating 25-hydroxy-vitamin D and risk of cardiovascular disease: a meta-analysis of prospective studies. Circ-Cardiovasc Qual 2012, 5:819-829.

32. Larsson SC, Virtamo J, Wolk A: Potassium, calcium, and magnesium intakes and risk of stroke in women. Am J Epidemiol 2011, 174:35-43.

33. Zhang W, Iso H, Ohira T, Date C, Tamakoshi A: Associations of dietary magnesium intake with mortality from cardiovascular disease: the JACC study. Atherosclerosis 2012, 221:587-595

34. Kousa A, Havulinna AS, Moltchanova E, Taskinen O, Nikkarinen M, Eriksson J, Karvonen M: Calcium:magnesium ratio in local groundwater and incidence of acute myocardial infarction among males in rural Finland. Environ Health Persp 2006, 114:730-734. 
35. Paik JM, Curhan GC, Sun Q, Rexrode KM, Manson JE, Rimm EB, Taylor EN: Calcium supplement intake and risk of cardiovascular disease in women. Osteoporos Int 2014, 25:2047-2056.

36. Balluz LSKS, Philen RM, Mulinare J: Vitamin and mineral supplement use in the United States. Results from the third National Health and Nutrition Examination Survey. Arch Fam Med 2000, 9:258-262.

37. Iso H, Stampfer MJ, Manson JE, Rexrode K, Hennekens CH, Colditz GA, Speizer FE, Willett WC: Prospective study of calcium, potassium, and magnesium intake and risk of stroke in women. Stroke 1999, 30:1772-1779.

38. Ministers NC: Nordic Nutrition Recommendations 2004: Integrating Nutrition and Physical Activity. Nord Counc Minist 2005.

39. Larsson SC, Orsini N, Wolk A: Dietary calcium intake and risk of stroke: a dose-response meta-analysis. Am J Clin Nutr 2013, 97:951-957.

40. Bolland MJ, Grey A, Gamble GD, Reid IR: Calcium and vitamin D supplements and health outcomes: a reanalysis of the Women's Health Initiative (WHI) limited-access data set. Am J Clin Nutr 2011, 94:1144-1149.

41. Wang L, Manson JE, Sesso HD: Calcium intake and risk of cardiovascular disease. Am J Cardiovasc Drug 2012, 12:105-116.

42. Keum N, Aune D, Greenwood DC, Ju W, Giovannucci EL: Calcium intake and colorectal cancer risk: dose-response meta-analysis of prospective observational studies. Int J Cancer 2014, [Epub ahead of print].

43. Bristow SM, Bolland MJ, MacLennan GS, Avenell A, Grey A, Gamble GD, Reid IR: Calcium supplements and cancer risk: a meta-analysis of randomised controlled trials. Br J Nutr 2013, 110:1384-1393.

44. Heaney RP, Kopecky S, Maki KC, Hathcock J, Mackay D, Wallace TC: A review of calcium supplements and cardiovascular disease risk. Adv Nutr 2012, 3:763-771.

45. Radford LT, Bolland MJ, Gamble GD, Grey A, Reid IR: Subgroup analysis for the risk of cardiovascular disease with calcium supplements. Bonekey Rep 2013, 2:293

46. Reid IR, Bolland MJ: Calcium supplements: bad for the heart? Heart 2012, 98:895-896

47. Mundy GR, Guise TA: Hormonal control of calcium homeostasis. Clin Chem 1999, 45:1347-1352.

48. Peacock M: Calcium metabolism in health and disease. Clin J Am Soc Nephro 2010, 5:S23-S30.

49. Resnick LM: The role of dietary calcium in hypertension A hierarchal overview. Am J Hypertens 1999, 12:99-112.

50. Allender P, Cutler J, Follmann D, Cappuccio F, Pryer J, Elliott P: Dietary calcium and blood pressure: a meta-analysis of randomized clinical trials. Ann Intern Med 1996, 124:825-831.

51. Zemel MB: Nutritional and endocrine modulation of intracellular calcium: implications in obesity, insulin resistance and hypertension. Mol Cell Biochem 1998, 188:129-136.

52. Draznin B: Intracellular calcium, insulin secretion, and action. Am J Med 1988, 85:44-58.

53. Rautiainen S, Wang L, Manson JE, Sesso HD: The role of calcium in the prevention of cardiovascular disease-a review of observational studies and randomized clinical trials. Curr Atheroscler Rep 2013, 15:1-23.

54. Leifsson B, Ahren B: Serum calcium and survival in a large health screening program. J Clin Endocr Metab 1996, 81:2149-2153.

55. Reid IR: Cardiovascular effects of calcium supplements. Nutrients 2013, 5:2522-2529.

56. Ärnlöv J, Carlsson AC, Sundström J, Ingelsson E, Larsson A, Lind L, Larsson TE: Higher fibroblast growth factor- 23 increases the risk of all-cause and cardiovascular mortality in the community. Kidney Int 2012, 83:160-166.

57. Dalal M, Sun K, Cappola AR, Ferrucci L, Crasto C, Fried LP, Semba RD: Relationship of serum fibroblast growth factor 23 with cardiovascular disease in older community-dwelling women. Eur J Endocrinol 2011, 165:797-803.

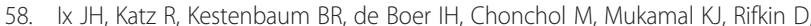
Siscovick DS, Sarnak MJ, Shlipak MG: Fibroblast growth factor-23 and death, heart failure, and cardiovascular events in community-living individuals: CHS (Cardiovascular Health Study). J Am Coll Cardiol 2012, 60:200-207.

59. Vervloet MG, van Ittersum FJ, Büttler RM, Heijboer AC, Blankenstein MA, ter Wee PM: Effects of dietary phosphate and calcium intake on fibroblast growth factor-23. Clin J Am Soc Nephro 2011, 6:383-389.

60. Wang TK, Bolland MJ, Pelt NC, Horne AM, Mason BH, Ames RW, Grey AB, Ruygrok PN, Gamble GD, Reid IR: Relationships between vascular calcification, calcium metabolism, bone density, and fractures. J Bone Miner Res 2010, 25:2777-2785.

61. Spence LA, Weaver CM: Calcium intake, vascular calcification, and vascular disease. Nutr Rev 2013, 71:15-22

62. Seely S: Is calcium excess in Western diet a major cause of arterial disease? Int J Cardiol 1991, 33:191-198.

63. Livingstone KM, Lovegrove JA, Cockcroft JR, Elwood PC, Pickering JE, Givens DI: Does dairy food intake predict arterial stiffness and blood pressure in men? Evidence from the Caerphilly Prospective Study. Hypertension 2013, 61:42-47.

doi:10.1186/s12916-014-0158-6

Cite this article as: Wang et al:: Dietary calcium intake and mortality risk from cardiovascular disease and all causes: a meta-analysis of prospective cohort studies. BMC Medicine 2014 12:158.

\section{Submit your next manuscript to BioMed Central and take full advantage of:}

- Convenient online submission

- Thorough peer review

- No space constraints or color figure charges

- Immediate publication on acceptance

- Inclusion in PubMed, CAS, Scopus and Google Scholar

- Research which is freely available for redistribution

Submit your manuscript at www.biomedcentral.com/submit
C Biomed Central 